\title{
Factors Influencing Adherence to Treatment and Quality of Life for a Group of Patients with Essential Hypertension in Romania
}

This article was published in the following Dove Press journal: Patient Preference and Adherence

\author{
Liana Suciu (D) \\ Maria Suciu' \\ Mirela Voicu (D) \\ Raluca Mureșan (D) ${ }^{2}$ \\ Florina Viorica Pârv $\mathbb{1}^{3}$ \\ Valentina Buda (D) ${ }^{\prime}$ \\ Carmen Cristescu' \\ 'Department of Pharmacology and \\ Clinical Pharmacy, Faculty of Pharmacy, \\ University of Medicine and Pharmacy \\ Victor Babeș, Timisoara, Romania; \\ ${ }^{2}$ Department of Mathematics, Faculty of \\ Mathematics and Informatics, West \\ University, Timisoara, Romania; \\ ${ }^{3}$ Department of Cardiology, Faculty of \\ Medicine, University of Medicine and \\ Pharmacy Victor Babeș, Timișoara, \\ Romania
}

Purpose: Romania has a high prevalence of hypertension (45.1\% in 2016). Whether this is attributable to a low rate of treatment adherence-which can aggravate the pathology and reduce patients' quality of life $(\mathrm{QoL})$ - is unknown. To address this point, the present study investigated the factors that influence short- and long-term adherence and QoL in patients with arterial hypertension using a specially designed questionnaire.

Patients and Methods: The study enrolled 289 patients at different stages of hypertension with or without comorbidities. The diagnosis of hypertension was established by the cardiologist, and treatment regimens were communicated by patients to the clinical pharmacist who administered the questionnaire, which comprised 7 domains with variable numbers of items. Results: The majority of surveyed patients $(57.43 \%)$ considered that their capacity for effort was decreased because of their hypertension, with $65.05 \%$ reporting that they were affected by symptoms associated with high blood pressure (eg, headache and dizziness). Most patients (71.28\%) understood the consequences of discontinuing their medication and the severe complications of hypertension, and $69.55 \%$ indicated that they would not stop treatment if they experienced side effects. For $53.28 \%$ of patients, social activity was significantly affected by their condition. Only $47.05 \%$ of patients underwent regular mandatory medical examinations and $55.36 \%$ periodically monitored their blood pressure at home. A regression analysis revealed correlations between specific questionnaire items and patient characteristics.

Conclusion: Nonpharmacologic factors that were shown to influence patients' adherence to treatment and QoL included the level of health education and knowledge of disease complications, self-monitoring of hypertension, and consultation with medical and pharmaceutical healthcare providers regarding hypertension and its treatment.

Keywords: arterial hypertension, quality of life, adherence, medication

\section{Introduction}

Individuals' state of health is closely associated with their quality of life (QoL), as a disease state can cause physical, mental, and social disability. Side effects of medication - especially in the case of loaded therapeutic regimens - can also diminish the QoL of patients. Given the increasing life expectancy especially in developed countries, various approaches have been used to identify indicators of a healthy life without disabilities so that the additional years are lived in a state of health as close as possible to a normal one. ${ }^{1}$ For example, health can be assessed through questionnaires that are generic or specific to a particular pathologic condition. $^{2-5}$
Correspondence: Maria Suciu; Mirela Voicu

Department of Pharmacology and Clinical Pharmacy, Faculty of Pharmacy, University of Medicine and Pharmacy Victor Babes, Eftimie Murgu Square, No. I-3, Timişoara România

Tel +40723319050; +40745763424

Email suciu.maria@umft.ro;

mavoicu@yahoo.com 
The results of the SEPHAR III study revealed a high proportion of patients with hypertension in Romania (45.1\%), which was associated with numerous risk factors and was attributable to a low standard of living; poor understanding of the condition and its complications as well as possible side effects of medications; and limited awareness of the importance of adopting a healthy lifestyle and diet. Hypertension and its complications can adversely affect patients' daily activities and lead to dissatisfaction, depression, and irritability.,

Given the chronic nature of essential hypertension and its association with multiple diseases, it is important to establish the factors contributing to its high prevalence in Romania. To this end, in this study, we used a specially designed questionnaire to identify factors affecting patients' shortand long-term adherence to therapy and QoL. Our findings highlight potentially modifiable factors that can be targeted by interventions to reduce the incidence of hypertension in Romania through improved clinical management.

\section{Materials and Methods}

\section{Study patients}

The study enrolled 289 hypertensive patients with different stages of hypertension. The period of the study development was between February and August 2013. The study was performed after a larger investigation of 357 hospitalized hypertensive patients who were administered the standardized SF-36v2 QoL questionnaire. As the results of that study did not address specific problems related to cardiovascular disease, a more specific questionnaire was developed that could identify additional pertinent issues. The present cohort comprised 289 hypertensive patients who met the following inclusion criteria: over the age of 18 years, with a diagnosis of primary hypertension at different stages of progression and with or without comorbidities and able to complete the questionnaire. The diagnosis of hypertension was established by a cardiologist and medications were communicated by patients to the pharmacist who conducted the interview. The questionnaire was administered to patients by the clinical pharmacist at an outpatient clinic and community pharmacies. The time taken to complete the questionnaire was 10-15 minutes.

\section{Informed Consent}

Patients were informed of the objectives of the study and were asked after they consented to participate in the study to complete the questionnaire under the guidance of the clinical pharmacist. The questionnaires were anonymous and numbered in order of evaluation, and did not contain patient identifiers.

\section{Ethics Approval}

This study was approved by the ethics committee of Victor Babes University of Medicine and Pharmacy (Timisoara, Romania) (approval no. 10/2013). The study was conducted in accordance with Declaration of Helsinki requirements.

\section{Questionnaire Design}

The questionnaire to assess the QoL of hypertensive patients comprised 7 domains with a variable number of items (questions) depending on the importance of the domain. The total number of questions was 22 . The items were scored from 1 to 5 on a Likert-like scale, with a higher number indicating a better QoL. The questionnaire evaluated the following: capacity for physical effort (domain 1); the patient's knowledge of their condition (domain 2); the importance of nonpharmacologic and pharmacologic treatments (domain 3); specific hypertension symptoms and potential cerebrovascular complications (domain 5); monitoring of the progression of the hypertension (domain 6); and adherence to treatment and emotional impact of the disease on patients' daily activities (domain 7). Domain 4 was removed from the final version of the questionnaire. The domains of the questionnaire were divided into 2 different categories: domains 1, 2 , 5 , and 7 were related to the patient's QoL, while domains 3, 4 , and 6 concerned the patient's adherence to therapeutic regimens, which indirectly influences QoL. The questionnaire was adequately validated, with a kappa coefficient $>0.75$ and Cronbach's alpha coefficient of $0.675 .^{4,5}$

\section{Statistical Analysis}

Data distribution was assessed with the KolmogorovSmirnov test. Data were analyzed with the Student's $t$ test or Mann-Whitney test. Statistical significance was set at $\mathrm{p}<0.05$. Regression analysis was performed with the backward elimination method. The quality of the regression model was assessed with Fisher's exact test.

\section{Results}

\section{Sociodemographic and Clinical}

\section{Characteristics of the Study Population}

The characteristics of the study population are presented in Table 1. 
Table I Sociodemographic and Clinical Characteristics of the Study Population

\begin{tabular}{|c|c|}
\hline Characteristics & $\begin{array}{l}\text { Number } \\
\text { (\%) }\end{array}$ \\
\hline \multicolumn{2}{|l|}{ Age, years } \\
\hline $30-39$ & $16(5.53)$ \\
\hline $40-49$ & $26(8.99)$ \\
\hline $50-59$ & $54(18.68)$ \\
\hline $60-69$ & $96(33.21)$ \\
\hline 70-79 & $67(23.18)$ \\
\hline$>80$ & $30(10.38)$ \\
\hline \multicolumn{2}{|l|}{ Education } \\
\hline Grades 4-8 & $76(26.29)$ \\
\hline Grades 9-12 & 128 (44.29) \\
\hline Secondary & $59(20.4 \mathrm{I})$ \\
\hline University & $26(8.99)$ \\
\hline \multicolumn{2}{|l|}{ Smoking } \\
\hline Yes & $63(21.79)$ \\
\hline \multicolumn{2}{|l|}{ Alcohol consumption } \\
\hline Yes & 39 (I3.49) \\
\hline \multicolumn{2}{|l|}{ Body mass index, $\mathrm{kg} / \mathrm{m}^{2}$} \\
\hline Normal weight (I8.5-24.9) & $54(18.68)$ \\
\hline Overweight (25.0-29.9) & $109(37.7 I)$ \\
\hline Obesity class I (30.0-34.9) & $96(33.21)$ \\
\hline Obesity class II (35.0-39.9) & $28(9.68)$ \\
\hline Obesity class III $(\geq 40)$ & $2(0.69)$ \\
\hline \multicolumn{2}{|l|}{$\begin{array}{l}\text { Time interval from initial diagnosis of arterial } \\
\text { hypertension, years }\end{array}$} \\
\hline$<1$ & $7(2.42)$ \\
\hline $1-5$ & $69(23.87)$ \\
\hline $6-10$ & $82(28.37)$ \\
\hline $1 \mathrm{I}-20$ & $85(29.4 I)$ \\
\hline$>20$ & $46(|5.9|)$ \\
\hline \multicolumn{2}{|l|}{$\begin{array}{l}\text { Number of comorbidities associated with arterial } \\
\text { hypertension }\end{array}$} \\
\hline $0-2$ & $163(56.4)$ \\
\hline 3 or 4 & 89 (30.79) \\
\hline 5 or 6 & $13(4.49)$ \\
\hline
\end{tabular}

In total, 289 patients $(50.51 \%$ female) completed the questionnaire. Most patients were 60-69 or 70-79 years of age (33.21\% and $23.18 \%$, respectively); $44.29 \%$ had secondary school education and $8.99 \%$ had postsecondary education. Nearly half of patients (43.61\%) were obese (defined as body mass index [BMI] $>30.0$ ), and $21.79 \%$ were smokers. The time since the initial diagnosis of hypertension ranged from 6 to 20 years. Comorbidities included coronary heart disease $(32.8 \%)$, dyslipidemia $(21.1 \%)$, diabetes $(17.3 \%)$, and stroke $(5.19 \%)$. Fewer than half of patients ( $\mathrm{n}=120,41.52 \%)$ had blood pressure values within normal limits.

The therapeutic regimens of the patients ranged from a single hypertensive drug to combinations of up to 4 drugs (Figure 1). Only 41 patients (14.18\%) were receiving fixed combinations of antihypertensive drugs. The most commonly prescribed drug types were betaadrenergic blockers (49.48\%), angiotensin-converting enzyme inhibitors (ACE-Is; 47.40\%), and thiazide-like diuretics (40.48\%) (Figure 2).

\section{Factors Influencing Patients' Treatment Adherence and QoL: Questionnaire Results}

The average scores of each domain in the questionnaire are presented in Table 2.

\section{Domain I}

Most patients (57.43\%) reported a reduced capacity for effort as a result of their condition, but also indicated that the pharmacologic intervention did not interfere with their daily activities (including light physical activities such as shopping, stair climbing, and walking).

\section{Domain 2}

Most patients (65.05\%) reported being affected by symptoms associated with hypertension such as headache and dizziness.

\section{Domain 3}

The majority of patients (71.28\%) were aware of the consequences of discontinuing their medication and the severe complications associated with hypertension; the same proportion of patients did not mind taking daily medication; $60.2 \%$ of patients indicated that they followed the imposed dietary and lifestyle recommendations (restricting salt and fat intake and quitting smoking); and $69.55 \%$ indicated that they did not use alternative antihypertensive treatments (natural remedies) and were not interested in knowing about them. The same percentage $(69.55 \%)$ of patients stated that they would not discontinue treatment in the event of side effects.

\section{Domain 4}

Although omitted from the final version of the questionnaire, the responses to the questions in this domain are worth mentioning: $64.01 \%$ of patients stated that they were satisfied with the medical services; however, more than half $(57.43 \%)$ reported that they did not receive 


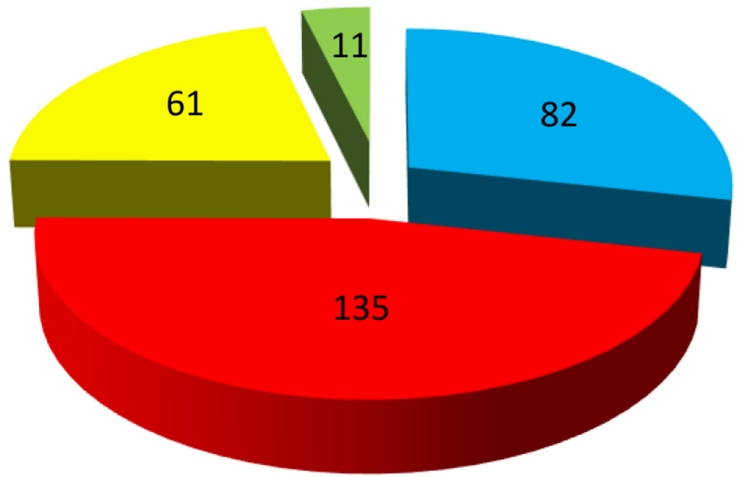

Monotherapy (28.37\%)

Dual therapy (46.71\%)

Triple therapy (21.10\%)

Cvadruple therapy

(3.80\%)

Figure I Types of therapeutic regimen administered to patients in this study. Numbers shown on each segment of the pie chart represent the number of patients for each type of regimen $(\mathrm{N}=289)$.

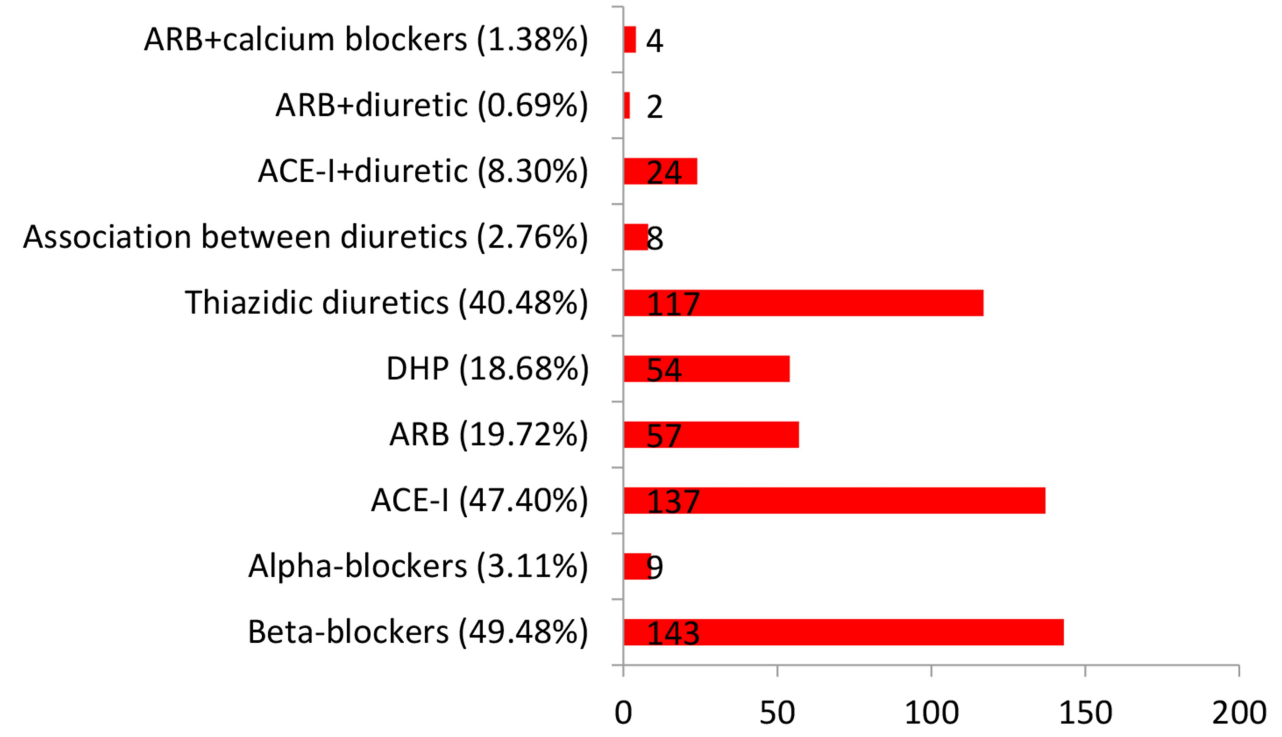

Figure 2 Types of antihypertensive drug in therapeutic regimens administered to patients in this study. The $x$-axis shows the number of patients receiving each type of drug. Abbreviations: ARB, angiotensin receptor blocker; ACE-I, angiotensin-converting enzyme inhibitor; DHP, dihydropyridine.

medication information at the pharmacy, or that they obtained information on the method of administration from the package of the medication, with no additional

Table 2 Results of the Different Domains of the Questionnaire

\begin{tabular}{|l|c|}
\hline Domain & Average Score \pm SD (Min-Max) \\
\hline \multicolumn{2}{|l|}{ Related to quality of life } \\
\hline 1 & $10.29 \pm 2.32(4.00-15.00)$ \\
2 & $5.50 \pm 1.68(2.00-10.00)$ \\
5 & $9.99 \pm 2.60(3.00-15.00)$ \\
7 & $13.62 \pm 1.64(10.00-18.00)$ \\
\hline Assessing compliance to treatment & \\
\hline 3 & $18.99 \pm 2.97(9.00-25.00)$ \\
4 & $6.87 \pm 1.84(2.00-10.00)$ \\
6 & $14.78 \pm 2.53(6.00-20.00)$ \\
\hline
\end{tabular}

Abbreviations: max, maximum; min, minimum; SD, standard deviation. information on drug action, possible side effects, or proper handling (time and frequency of administration, storage instructions, etc.) given by healthcare providers.

\section{Domain 5}

Symptoms reported by patients included drowsiness, fatigue, and dizziness (47.05\%). However, it was unclear whether these symptoms were due to hypertension or the side effects of antihypertensive medication. For $53.28 \%$ of patients, social activities were significantly affected by hypertension.

\section{Domain 6}

Only $47.05 \%$ of patients underwent regular medical examinations; $55.36 \%$ of patients periodically monitored their blood pressure values at home; and $56.40 \%$ were aware of the fatal complications associated with very high blood pressure (eg, accidental stroke, acute myocardial 
infarction). Nonetheless, $92.73 \%$ of patients knew that antihypertensive treatment should be followed for life.

\section{Domain 7}

Hypertension had a higher impact on the emotional state of patients than on the other evaluated domains. The first two questions evaluated anxiety associated with hypertension; only $31.14 \%$ of patients did not experience anxiety in relation to their condition. In terms of depression, $24.91 \%$ of patients felt that their condition prevented them from playing a useful role in professional and family activities.

We examined whether responses in specific domains of the questionnaire were correlated with patients' sociodemographic characteristics, comorbidities associated with hypertension, and the types of antihypertensive drug in treatment regimens by multivariate linear regression analysis and the results are listed in the next table (Table 3).

According to this regression model: age, education, number of hypertensive drugs and initial values of arterial hypertension are negatively correlated with D1, D2, D3 domains. Individual characteristics such as smoking, obesity are also associated negatively with D5, D6, D7 domains. Regarding the medication, beta-blockers are also negatively correlated with D1 and D3 domains and statins on D2 and D3 have the same results.

Table 3 Results of the Multivariate Linear Regression Analysis of Factors Influencing Treatment Adherence and Quality of Life in Patients with Hypertension

\begin{tabular}{|c|c|c|c|c|c|c|}
\hline Variables & DI & D2 & D3 & D5 & D6 & D7 \\
\hline Regression steadiness & 9.881 & 5.818 & $|5.64|$ & 8.064 & 9.150 & 4.249 \\
\hline $\begin{array}{l}\text { Sociodemographic and clinical characteristic } \\
\text { Age }\end{array}$ & -0.046 & -0.027 & -0.065 & & & \\
\hline $\begin{array}{l}\text { Sex } \\
\text { Education } \\
\text { Smoking } \\
\text { Alcohol consumptions }\end{array}$ & -0.512 & & $\begin{array}{l}-0.639 \\
-1.941\end{array}$ & -1.121 & 0.0617 & \\
\hline $\begin{array}{l}\text { Duration of hypertension } \\
\text { Body mass index } \\
\text { Total number of drugs } \\
\text { Number of antihypertensive drugs } \\
\text { Fixed drug combinations } \\
\text { Comorbidities associated with arterial hypertension } \\
\text { Initial systolic blood pressure } \\
\text { Initial diastolic blood pressure } \\
\text { Final blood pressure value }\end{array}$ & $\begin{array}{l}0.191 \\
0.504 \\
\\
-0.037 \\
0.071\end{array}$ & $\begin{array}{l}0.073 \\
0.297 \\
-0.534\end{array}$ & $\begin{array}{l}1.656 \\
0.581 \\
-0.025 \\
0.056\end{array}$ & $\begin{array}{l}2.088 \\
-0.053 \\
0.053 \\
0.044\end{array}$ & $\begin{array}{l}-0.091 \\
-0.194 \\
0.013\end{array}$ & $\begin{array}{l}-0.039 \\
0.163\end{array}$ \\
\hline $\begin{array}{l}\text { Types of antihypertensive drug } \\
\text { Beta-blocker } \\
\text { Alpha-blocker } \\
\text { ACEI } \\
\text { Angiotensin II ATI receptor inhibitor } \\
\text { Dihydropyridine } \\
\text { Loop of Henle diuretic } \\
\text { Thiazide and thiazide-like diuretic } \\
\text { Antialdosterone diuretic } \\
\text { Diuretic combinations } \\
\text { Statin } \\
\text { Fibrate } \\
\text { Anti-aggregating platelets } \\
\text { Anticoagulant } \\
\text { ACE-I+diuretic }\end{array}$ & $\begin{array}{l}-4.914 \\
-3.094\end{array}$ & $\begin{array}{l}-0.991 \\
-1.013 \\
-1.970\end{array}$ & $\begin{array}{l}-1.074 \\
1.068 \\
\\
2.430 \\
-1.87 \mid\end{array}$ & $\begin{array}{l}1.052 \\
-5.694 \\
\end{array}$ & -0.757 & $\begin{array}{l}-0.219 \\
-0.187 \\
-1.597 \\
-0.206\end{array}$ \\
\hline
\end{tabular}

(Continued) 
Table 3 (Continued).

\begin{tabular}{|c|c|c|c|c|c|c|}
\hline Variables & DI & D2 & D3 & D5 & D6 & D7 \\
\hline $\begin{array}{l}\text { ARB+diuretic } \\
\text { ARB+calcium blocker } \\
\text { Anxiolytic } \\
\text { NSAIDs }\end{array}$ & & & & $\begin{array}{l}-2.065 \\
3.773\end{array}$ & & $-1.09 \mid$ \\
\hline $\begin{array}{l}\text { Comorbidities } \\
\text { Coronary disease } \\
\text { Left ventricular hypertrophy } \\
\text { Valvulopathy } \\
\text { Valve prosthesis } \\
\text { Arrhythmias } \\
\text { Heart failure } \\
\text { Dyslipidemia } \\
\text { Obesity } \\
\text { Diabetes } \\
\text { Strokes } \\
\text { Anemia }\end{array}$ & $\begin{array}{r}4.205 \\
-1.859\end{array}$ & & $\begin{array}{l}1.232 \\
-2.068\end{array}$ & $\begin{array}{l} \\
-5.387 \\
1.679 \\
\\
1.022 \\
8.271\end{array}$ & 0.770 & $\begin{array}{l}0.459 \\
-1.755\end{array}$ \\
\hline $\begin{array}{l}\text { Chronic kidney failure } \\
\text { Liver pathology } \\
\text { Pulmonary infarction } \\
\text { Bronchial asthma/COPD/sleep apnea } \\
\text { Basedow disease } \\
\text { Spondylosis } \\
\text { Osteoporosis } \\
\text { Anxiety syndrome } \\
\text { Digestive pathology (gastric/duodenal ulcer/gastritis) }\end{array}$ & 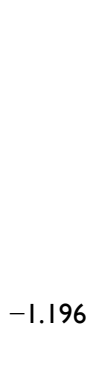 & & -2.993 & $\begin{array}{l}2.770 \\
-2.702 \\
-3.043\end{array}$ & & $\begin{array}{l}0.630 \\
1.294 \\
-2.840\end{array}$ \\
\hline $\mathrm{R}^{2}$ & 0.376 & 0.266 & 0.448 & 0.391 & 0.167 & 0.241 \\
\hline $\mathrm{R}^{2}$ adjusted & 0.319 & 0.210 & 0.380 & 0.304 & 0.128 & 0.160 \\
\hline SD & 2.248 & 1.613 & 2.122 & 2.278 & 1.368 & 0.806 \\
\hline$F$ & 6.577 & 4.749 & 6.547 & 4.525 & 4.247 & $2.97 I$ \\
\hline P & 0.0001 & 0.0001 & 0.0001 & 0.0001 & 0.0001 & 0.0001 \\
\hline
\end{tabular}

Abbreviations: NSAIDs, nonsteroidal anti-inflammatory drugs; ARB, angiotensin receptor blocker; ACE-I, angiotensin-converting enzyme inhibitor; COPD, chronic obstructive pulmonary disease.

\section{Discussion}

In this study, we designed a specific questionnaire to assess adherence to treatment and QoL in patients with arterial hypertension in order to identify possible causes of failure to maintain blood pressure within normal limits in a large portion of the Romanian population.

Age and female sex were identified as risk factors for hypertension in the SEPHAR I and SEPHAR II studies. ${ }^{8-11}$ In the present study, $21.79 \%$ of patients with hypertension were smokers and $43.58 \%$ had BMI $>30$, indicating that an unhealthy lifestyle contributes to the high prevalence of hypertension in Romania. The time from the initial diagnosis of primary hypertension was between $10-20$ years for $29.41 \%$ of patients and $>20$ years for $15.91 \%$. Therefore, for nearly half of the patients in our study, hypertension was a chronic condition that likely had variable impact on patients' health and QoL over time. On the other hand, $56.4 \%$ of patients did not have any or up to two comorbidities, which is at odds with the length of time since the diagnosis of hypertension. The discrepancy may be explained by insufficient medical control or ignorance of comorbidities. Most patients initially had stage 3 hypertension, and only $41.52 \%$ reported normalized blood pressure after treatment, which is in 
accordance with findings from the SEPHAR III study. ${ }^{6,7}$ The low rate of therapeutic response cannot be ascribed to pharmacotherapy regimens because almost half of the patients (46.71\%) used at least two drugs and $21.1 \%$ received antihypertensive triple therapy. Most patients in our study did not know the doses of drugs in their therapeutic regimens. The most commonly prescribed antihypertensive drugs were beta-blockers $(49.48 \%)$, but this was unrelated to patients' age; $37.76 \%$ of patients who received these drugs were between 50 and 65 years old and $46.85 \%$ were $>65$ years old. The latter age group had a higher incidence of coronary heart disease or heart failure, which could justify the choice of this class of antihypertensive medication, which is recommended by European Guidelines for the Management of Hypertension. ${ }^{8,9}$

ACE-Is rank second among drugs prescribed for hypertension, most commonly used being perindopril or ramipril. Angiotensin II AT1 receptor blockers are infrequently prescribed (19.72\%), as their efficacy is comparable to that of ACE-Is; ${ }^{12-14}$ the same applies to dihydropyridines (18.68\%). ${ }^{12,13}$ Current guidelines for the management of hypertension recommend dihydropyridines over betablockers. ${ }^{12,13}$ Although many fixed combinations of antihypertensive drug have been approved for clinical use in recent years, this was used by only $14.18 \%$ of patients in our cohort, with perindopril and indapamide being the most common combination. ${ }^{15}$

The sociodemographic and clinical characteristics of the patients in this study are concordant with national epidemiologic studies on patients with hypertension (SEPHAR I and II). ${ }^{9}$ We found a positive correlation between patient age and duration of hypertension, number of comorbidities, and number of drugs in the treatment regimen. The multivariate linear regression analysis showed that patient age was negatively correlated with domains 1 to 3 of the questionnaire and influenced daily physical activity and potentiated symptoms of hypertension or its complications while negatively affecting treatment adherence, which is in accordance with other studies evaluating the QoL of patients with hypertension. ${ }^{16-18}$

The scores in domain 1 were lower than those in the other domains and highlight the negative effect of hypertension and comorbidities on physical mobility. Domain 2 evaluated the presence of hypertension symptoms and complications. Patients were generally aware of and many reported experiencing the symptoms of high blood pressure; however, $44.98 \%$ did not have symptoms, especially in patients with few comorbidities. Domain 3 evaluated treatment adherence in the patients; most were aware of dietary restrictions imposed by hypertension or the consequences of discontinuing pharmacologic treatment, in contrast to other studies in which patients believed that if blood pressure values normalized or hypertension symptoms disappeared, then it was no longer necessary to take their medication. ${ }^{16}$ Additionally, $69.55 \%$ of patients reported not using alternative treatment methods or indicated that they would not stop taking their medication in the event of side effects without medical consultation; this also diverges from previous reports of patients who believed that the treatment would cure their hypertension. ${ }^{16,17}$ Situations such as omitting some doses or forgetting to take the medication as well as financial considerations prohibiting the purchase of medicines were not mentioned in the questionnaire, although these are factors that could influence treatment adherence and consequently, its efficacy.

Domain 4 evaluated the patient's relationship with medical and pharmaceutical staff. This domain was omitted from the final version of the questionnaire after analyzing the internal consistency based on Cronbach's alpha coefficient, because it did not directly reflect factors that influence QoL. However, the patients' responses indicated an unsatisfactory relationship with healthcare professionals, which could have consequences for the patients (eg, refraining from requesting additional consultations in the event of changes in health status, missing scheduled appointments, or being misinformed about the health impacts of their medication or lifestyle). Our results are consistent with those of other compliance studies demonstrating that patients received insufficient explanation regarding the disease, symptoms, complications, and treatment. ${ }^{18-21}$

Domain 5 evaluated how the symptoms of hypertension or side effects related to antihypertensive medication interfere with patients' professional, social, and sexual activities. In most cases, patients' activities were negatively affected, except for the question regarding intimate relationships: many patients either did not answer this question, or responded that they had no problems in this regard. Our findings are in agreement with other reports that hypertension itself or its inadequate monitoring and treatment affected patients' daily activities..$^{19,21}$

Domain 6 evaluated patients' compliance with treatment. Most patients did not consider that regular medical check-ups were necessary unless their health status 
deteriorated. Monitoring blood pressure at home was not an alternative for half of the patients in our cohort. In the SEPHAR I study conducted in 2005 , only $19.9 \%$ of hypertensive patients in Romania had normalized blood pressure values; in the SEPHAR III survey in 2016, the proportion was $30.8 \%^{6,9}$ and $42.57 \%$ of patients gave a negative answer to the question "Do you think that you could suffer a heart attack or stroke because of high blood pressure?" These patients were unaware of the fatal or debilitating complications of high blood pressure, which is consistent with other treatment compliance studies. ${ }^{17}$

Domain 7 pertaining to the emotional impact of hypertension on the patient had low scores for both anxiety and depression. Cognitive, sensory, and psychomotor deficits were observed in untreated patients with hypertension, but these symptoms improved after treatment. Patients with hypertension also complained of sleep disorders and greater emotional lability compared to normotensive patients. Our findings support those of earlier studies demonstrating that effective blood pressure control had clear emotional and psychological benefits and improved sleep quality. ${ }^{22-24}$

Domains 3, 4, and 6 assessed patients' adherence to treatment. Patients' responses to questions in these domains indicated an unsatisfactory relationship with medical and pharmaceutical staff; consequently, patients were unaware of the need for regular medical evaluations, did not self-monitor their blood pressure values, and lacked knowledge regarding their condition and its long-term complications and treatment. The regression analysis showed that domain 1 was negatively impacted by age, initial blood pressure values, obesity, and anxiety, which is in accordance with previous findings although in some studies age had no significant effect on treatment adherence. $^{22,23}$ Domains 3 and 5, which addressed smoking in patients with hypertension, were influenced by comorbidities (eg, obesity and thyroid disease) or valve replacement; patients with multiple pathologies showed low compliance with treatment, which was also reflected in the responses to questions in domains 6 and 7.

We included different classes of drug in the regression model, which showed that beta-blockers, anti-aldosterone diuretics, and antiplatelet agents had a negative impact on domain 1 while thiazide and loop diuretics negatively influenced domains 5 and 6 . This may be attributable to the side effects of medications (eg, hypotension with risk of dizziness, numbness, and falls; impaired concentration; sleep disorder; frequent urination; hyperacidity). ACE-Is and sartans negatively influenced domain 7 (emotional impact) and statins affected domain 3 (treatment adherence). Antiplatelet agents and anticoagulants had a negative impact on domains 1, 2, and 3, and anxiolytics influenced domains 5 and 6, which is in accordance with previous observations that hypertension influences the emotional state of patients. Thus, medication was a major factor that influenced patient adherence to treatment; as a loaded therapeutic regimen was unappealing, many patients adjusted their treatment by eliminating some drugs that they considered unnecessary.

The regression analysis showed low correlations between comorbidities and the various domains of the questionnaire, except for the negative impact on domain 7 (emotional component) and domain 3 (adherence to treatment), which is in line with other reports. ${ }^{24-26}$

\section{Conclusion}

The questionnaire developed in this study, which directly assessed QoL as well as factors influencing treatment adherence, was useful in terms of the complex information that it provided about patients with hypertension in Romania, including their knowledge of hypertension and its symptoms and aims and possible side effects of treatment regimens, and their relationship with healthcare providers and how this influenced short- and long-term treatment adherence. The latter also revealed the degree of patient satisfaction regarding the clinical management of their condition. The questionnaire was unique in that it addressed different aspects of therapeutic regimens (eg, number of drugs, adverse events, dosages) that could impact patients' treatment adherence and QoL, and is applicable to both clinical practice and clinical research studies. We identified multiple factors that negatively influenced patients' treatment adherence and QoL including insufficient knowledge about hypertension, its progression, and prognosis; lack of awareness of the importance of regular medical examinations and self-monitoring; and unsatisfactory relationships with healthcare providers (doctors, nurses, and pharmacists). These are areas that can be specifically targeted by interventions to reduce the high prevalence of hypertension in Romania, which is critical given that hypertension and associated pathologies adversely affect patients' social activities and emotional state and its complications (eg, stroke, heart attack, heart failure) incur high costs for patients as well as the healthcare system. 


\section{Disclosure}

The authors report no conflicts of interest in this work.

\section{References}

1. World Health Organization. International classification of functioning, disability and health; 2001. Available from: https://www.who.int/ docs/default-source/classification/icf/official-icf-updates/2011icfup dates.pdf?sfvrsn=485cb584_2. Accessed December 20, 2020.

2. Carvalho MA, Silva IB, Ramos SB, et al. Quality of life of hypertensive patients and comparison of two instruments of HRQoL measure. Arq Bras Cardiol. 2012;98:442-510. doi:10.1590/S0066782X2012005000032

3. Morisky DE, Green LW, Levine DM. Concurrent and predictive validity of a self-reported measure of medication adherence. Med Care. 1986;24:67-74. doi:10.1097/00005650-198601000-00007

4. Korb-Savoldelli V, Gillaizeau F, Pouchot J, et al. Validation of a French version of the 8-item Morisky medication adherence scale in hypertensive adults. $J$ Clin Hypertens (Greenwich). 2012;14:429-434. doi:10.1111/j.1751-7176.2012.00634.x

5. Melchiors AC, Correr CJ, Pontarolo R, et al. Quality of life in hypertensive patients and concurrent validity of Minichal-Brazil. Arq Bras Cardiol. 2010;94:337-344. doi:10.1590/s0066$782 \times 2010000300013$

6. Dorobantu M, Tautu OF, Dimulescu D, et al. Perspectives on hypertension prevalence treatment and control in a high cardiovascular risk East European country (data from the Sephar III survey). J Hypertens. 2018;36:690-700. doi:10.1097/HJH.0000000000001572

7. Dorobantu M, Darabont R, Dimulescu D, et al. New epidemiologic national representative survey. Sephar III main results. J Hypertens. 2017;35:pe60. doi:10.1097/01.hjh.0000523132.85277.15

8. Dorobantu M, Darabont RO, Badila E, et al. Prevalence, awareness, treatment and control of hypertension in Romania: results of the Sephar Study. Int J Hypertens. 2010;2010:970694. doi:10.4061/ 2010/970694

9. Dorobantu M, Darabont R, Ghiorghe S, et al. Hypertension prevalence and control in Romania at a seven-year interval. Comparison of Sephar I and II surveys. J Hypertens. 2014;32:39-47. doi:10.1097/01. hjh.0000434937.62412.24

10. Dorobanţu M, Bartoş D, Apetrei E, et al. Hypertension in Romania: where are we and what can we do? Results from SEPHAR II study. Rom J Cardiol. 2012;22:285-292.

11. Rana BK, Insel PA, Payne SH, et al. Population-based sample reveals gene-gender interactions in blood pressure in White Americans. Hypertension. 2007;49:96-106. doi:10.1161/01.HYP.0000252029 .35106 .67

12. Mancia G, Fagard R, Narkiewicz K, et al. Guidelines for the management of arterial hypertension: the Task Force for the Management of Arterial Hypertension of the European Society of Hypertension (ESH) and of the European Society of Cardiology (ESC). J Hypertens. 2013;31:1281-1357. doi:10.1097/01.hjh.0000431740.32696.cc
13. Williams B, Mancia G, Spiering W, et al. ESC/ESH guidelines for the management of arterial hypertension: the Task Force for the Management of Arterial Hypertension of the European Society of Cardiology ESC and the European Society of Hypertension ESH. J Hypertens. 2018;37:1953-2041.

14. Ogilvie RI, Anand S, Roy P, et al. Perindopril for control of blood pressure in patients with hypertension and other risk factors: an open label, observational, multicentre, general-practice-based study. Clin Drug Investig. 2008;28:673-686. doi:10.2165/00044011-20082811000001

15. Mourad JJ, Le Jeune S. Evaluation of high dose of perindopril/ indapamide fixed combination in reducing blood pressure and improving end-organ protection in hypertensive patients. Curr Med Res Opin. 2009;25:2271-2280. doi:10.1185/03007990903186787

16. Ross S, Walker A, MacLeod MJ. Patient compliance in hypertension: role of illness perceptions and treatment beliefs. J Hum Hypertens. 2004;18:607-613. doi:10.1038/sj.jhh.1001721

17. Abbas H, Kurdi M, Watfa M, et al. Adherence to treatment and evaluation of disease and therapy knowledge in Lebanese hypertensive patients. Patient Prefer Adherence. 2017;11:1949-1956. doi:10.2147/PPA.S142453

18. Katsi V, Kallistratos MS, Kontoangelos K, et al. Arterial hypertension and health related quality of life. Front Psychiatry. 2017;8:270. doi:10.3389/fpsyt.2017.00270

19. Cavalcante MA, Bombiq MT, Luna Filho B, et al. Quality of life of hypertensive patients treated at an outpatient clinic. Arq Bras Cardiol. 2007;89:245-250. doi:10.1590/s0066-782×2007001600006

20. Xiao M, Zhang F, Xiao N, et al. Health-related quality of life of hypertension patients: a population based cross sectional study in Chongqing, China. Int J Environ Res Public Health. 2019;16:2348. doi:10.3390/ijerph16132348

21. Youssef RM, Moubarak II, Kamel MI. Factors affecting the quality of life of hypertensive patients. East Mediterr Health J. 2005;11:109-118.

22. Cuffee Y, Ogedegbe C, Williams NJ, et al. Psychosocial risk factors for hypertension. An update of the literature. Curr Hypertens Rep. 2014;16:483. doi:10.1007/s11906-014-0483-3

23. Bacon SL, Campbell TS, Arsenault A, et al. The impact of mood and anxiety disorders on incident hypertension at one year. Int J Hypertens. 2014;2014:953094. doi:10.1155/2014/953094

24. Osman EM, Suleiman I, Elzubair AG. Patients knowledge of hypertension and its control in Eastern Sudan. East Afr Med J. 2007;84:324-328. doi:10.4314/eamj.v84i7.9587

25. Vierra AJ, Cohen LW, Mitchell CM, et al. High blood pressure knowledge among primary care patients with known hypertension: a North Carolina Family Medicine Research Network (NC-FMR-RN) study. J Am Board Fam Med. 2008;21:300-308. doi:10.3122/ jabfm.2008.04.070254

26. Ho PM, Bryson CL, Rumsfeld JS. Medication adherence: its importance in cardiovascular outcomes. Circulation. 2009;119:3028-3035. doi:10.1161/CIRCULATIONAHA.108.768986
Patient Preference and Adherence

\section{Publish your work in this journal}

Patient Preference and Adherence is an international, peer-reviewed, open access journal that focusing on the growing importance of patient preference and adherence throughout the therapeutic continuum. Patient satisfaction, acceptability, quality of life, compliance, persistence and their role in developing new therapeutic modalities and compounds to optimize clinical outcomes for existing disease states are major areas of interest for the journal. This journal has been accepted for indexing on PubMed Central. The manuscript management system is completely online and includes a very quick and fair peer-review system, which is all easy to use. Visit http:// www.dovepress.com/testimonials.php to read real quotes from published authors. 